\title{
POSSIBILIDADES PARA ENSINAR CONCEITOS DE FORÇA DE ARRASTO EM MEIO LÍQUIDO
}

\section{POSSIBILITIES FOR TEACHING CONCEPTS OF DRAG FORCE IN A LIQUID MEDIUM}
A. S. FONTES ${ }^{1}$,
O. R. SANTOS ${ }^{2}$,
M. C. BATISTA ${ }^{1}$
${ }^{1}$ Universidade Tecnológica Federal do Paraná.
${ }^{2}$ Mestrado Nacional Profissional em Ensino de Física.

\begin{abstract}
Resumo
Neste trabalho apresentamos algumas possibilidades para se trabalhar força de arrasto em meios viscosos. A Sequência didática desenvolvida foi aplicada na disciplina de Física 1, em uma turma contendo 13 alunos do curso Superior de Licenciatura em Química, de uma Universidade Pública no interior do Paraná. O assunto abordado, faz parte da ementa da disciplina. Para levantar os conhecimentos prévios dos alunos sobre o assunto foi aplicado um Quiz na plataforma do Kahoot. Após, foram realizadas aulas expositivo-dialogadas e na sequência, atividades práticas virtuais através de simuladores e uma atividade prática experimental no laboratório de Física utilizando a vídeo-análise por meio do software Tracker, Open Camera e o editor de planilhas do Excel, os quais possibilitaram a investigação do comportamento de uma esfera em queda em três meios viscosos, quadro a quadro. Os resultados indicaram que a SD e atividades experimentais aliada às Tecnologias Digitais de Informação e Comunicação (TDICs) possibilitaram trabalhar os conceitos físicos envolvidos os materiais utilizados nos experimentos reais, são de baixo custo e de fácil reprodução e as atividades realizadas, por meio das TDIC, são de amplo acesso e permitem realizar práticas com rapidez e qualidade.
\end{abstract}

Palavras-chave: Sequência didática. Força viscosa. TDIC. 


\begin{abstract}
In this work we present some possibilities for working with drag force in viscous medium. The didactic Sequence developed was applied in the discipline of Physics 1, to a class containing 13 students of the Higher Degree in Chemistry, at a Public University in the interior of Paraná. The subject addressed is part of the discipline's menu. To survey the students' prior knowledge on the subject, a Quiz was applied on the Kahoot platform. Afterwards, expository-dialogued classes were carried out and, in sequence, virtual practical activities through simulators and an experimental practical activity in the Physics laboratory using video analysis using the software Tracker, Open Camera and the Excel spreadsheet editor, which made it possible to investigate the behavior of a falling sphere in three viscous media, frame by frame. The results indicated that the SD combined with the Digital Technologies of Information and Communication (TDICs) made it possible to work on the physical concepts involved, as the materials used in real experiments are low cost and easy to reproduce and the activities carried out by means of TDIC are widely accessible and allow practices to be carried out quickly and with quality.
\end{abstract}

Keywords: Teaching Sequence. Viscous force. DICT

\title{
I. INTRODUÇÃO
}

Com o avanço crescente da tecnologia e o fácil acesso, a informação tem chegado mais rápido, desta forma a tecnologia se tornou grande aliada para todos os segmentos. Nas instituições de ensino, tem proporcionado novas formas de compreender e de realizar o trabalho pedagógico; mais competências estão sendo exigidas; e é imprescindível preparar o licenciando na Universidade e formar continuamente o professor regente, para atuar neste ambiente tecnológico, em que a tecnologia serve como intercessor do processo ensinoaprendizagem (OLIVEIRA; MOURA SOUSA, 2015).

Segundo Silva et al. (2018), observando o comportamento dos alunos, verifica-se que eles têm fácil acesso a instrumentos digitais, aplicativos, jogos, tendo incorporado em sua linguagem assuntos relacionados ao uso dessas mídias.

Eles precisam de um ambiente no qual o professor faça uso de metodologias ativas, utilizando recursos compostos pelas tecnologias digitais, com a finalidade de proporcionar motivação. Além disso, é preciso criar espaços de aprendizagem, sejam na escola ou fora dela, que se apropriem de metodologias de ensino associadas aos recursos digitais, tais como os objetos de aprendizagem, ambientes virtuais ou softwares (SILVA et al., 2018). Assim, os recursos tecnológicos como os simuladores e aplicativos podem ser considerados fortes aliados para construção de um ensino potencialmente significativo (MOREIRA, 2011).

Existem uma diversidade de recursos tecnológicos que pode ser utilizado no ensino, entre eles o Kahoot $^{1}$ (plataforma de aprendizado baseada em jogos), que é uma plataforma interativa que incorpora elementos utilizados no design de jogos para engajar os usuários na aprendizagem. Uma das características dessa ferramenta, que pode ser utilizada tanto

\footnotetext{
${ }^{1}$ Disponível em: <https://kahoot.com/>
} 
dentro, quanto fora da sala de aula, é despertar a curiosidade e o envolvimento dos alunos em experiências para impactar positivamente sua performance de aprendizagem (GAZOTTIVALLIM; GOMES; FISCHER, 2017).

Dentre as atividades no Kahoot, os Quizzes são os mais utilizados pelos docentes, pois são questionários de múltipla escolha, com correção automática, cuja finalidade é avaliar de forma rápida e divertida, utilizando para isso a técnica da gamificação, para envolver, motivar, atrair a atenção e promover a aprendizagem (DETERDING et al., 2011 apud SILVA et al, 2018). Ele também pode ser utilizado como instrumento de avaliação diagnóstica, formativa e/ou somativa, e ainda para verificar o conhecimento prévio dos alunos sobre determinado assunto, introduzir conteúdo, verificar a aprendizagem, ou para realizar uma revisão dos conteúdos trabalhados.

Existem disponíveis na internet, vários recursos educacionais muito úteis para o ensino de Física, entre eles, simuladores que reproduzem atividades experimentais disponíveis, por exemplo, pelo NOAS² ( Núcleo de Desenvolvimento de Objetos de Aprendizagem Significativa), do Colégio Cenecista Dr. José Ferreira, Uberaba (MG), destinado ao desenvolvimento de objetos de aprendizagem significativa, estruturados em simulações computacionais de fenômenos; e pelo Projeto do PhET ${ }^{3}$ ("Physics Education Technology") Simulações Interativas, da Universidade de Física do Condado de Boulder, Colorado (EUA Estados Unidos da América), o qual cria e disponibiliza simulações interativas gratuitas de matemática e ciências, apresentando uma diversidade de conteúdos abordados as quais podem ser testados pelos usuários

Outra Tecnologia Digital de Informação e Comunicação (TDIC), muito útil no ensino de Física é a vídeo-análise, realizada por meio do software Tracker ${ }^{4}$, o qual possibilita analisar vídeos, ou uma sequência de imagens quadro a quadro, com o intuito de acompanhar e conhecer a posição de um objeto no decorrer do tempo. Os dados obtidos dão origem a tabelas e gráficos nos quais podem ser analisadas posição, velocidade e aceleração, dentre outros aspectos.

Para a sua utilização são necessários apenas um computador e um instrumento para a captação de imagens tal como um a filmadora, celular ou máquina digital (ORTIZ, 2015). Com esse software, professores e alunos podem criar, filmar e analisar experimentos com câmeras digitais caseiras, reduzindo os custos operacionais e o tempo de preparação dos experimentos (MARTINS et al, 2013).

Outra ferramenta, com muito potencial é o $A \operatorname{lgodoo^{5}}$, que é um software lúdico, de simulação 2D exclusivo da Algoryx Simulation AB o qual possibilita criar cenas interativas, para reproduzir os fenômenos da natureza, sendo analisados em inúmeras situações.

Por meio desse ambiente de desenvolvimento, os profissionais da área de ensino, podem reproduzir um laboratório de Física virtual, contendo ferramentas que possibilitam construir ensaios de cada conteúdo abordado, o que seria dificultoso e limitado quando reproduzidos em laboratório físico. Nesse sentido, nosso trabalho objetiva apresentar uma SD, para o ensino de força de arrasto em um meio líquido, utilizando atividades práticas através das

\footnotetext{
${ }^{2}$ Disponível em: <http://www.noas.com.br/ensino-medio/>

${ }^{3}$ Disponível em: <https://phet.colorado.edu/>

${ }^{4}$ Disponível em: <http://physlets.org/tracker/>

${ }^{5}$ Disponivel em: http://www.algodoo.com/download/
} 
TDIC.

\section{FUNDAMENTAÇÃO TEÓRICA}

\section{II.1. Força de atrito}

Conceitualmente, força é um conceito relacional que quantifica a interação entre partes de um sistema físico. Isso significa que, dado um sistema físico, dividido em duas partes, a força é o cômputo da taxa temporal de transferência de momento de uma parte para outra, tal que, se o sistema físico estiver isolado, a quantidade de momento que é recebida por uma parte é igual à quantidade de momento perdida pela outra parte.

No âmbito da mecânica de meios contínuos, as forças podem ser classificadas em forças de volume e forças de superfície. Forças de volume aparecem quando temos forças gravitacionais e forças eletromagnéticas não blindadas (corpos macroscopicamente neutros). Forças de superfície aparecem quando temos forças eletromagnéticas blindadas, de modo a reduzir sua escala de comprimento.

É possível identificar uma força de atrito cinético entre sólidos em contato, se formos capazes de estabelecer, no contato, uma velocidade relativa de escorregamento diferente de zero, para as superfícies em contato, que escorregam uma em relação a outra (CALDAS E SANTIEL, 1999).

Segundo Caldas e Santiel (1999), para existir força de atrito estático entre dois sólidos, é necessário que não haja velocidade relativa de escorregamento entre eles, esta força tem origem em ligações químicas formadas entre átomos vizinhos pertencentes aos distintos corpos "em contato", além disso, uma força externa (ou resultante de forças ou torques) não nula, esteja atuando sobre o sistema. Estas são condições essenciais para a existência do atrito estático, caso contrário, a resultante das forças de contato seria normal as superfícies de contato, não havendo componentes tangenciais.

A Força de Arrasto, está presente em meios fluídos (líquidos e gases) onde, interferem na velocidade do objeto em estudo, ela é modelada empiricamente, por formas funcionais onde constam parâmetros que permitem o ajuste da forma funcional, através de experimentos, este modelo leva em consideração o coeficiente de arrasto, e as dimensões e área superficial.

A força de atrito age em porções muito pequenas, à medida que um corpo desliza sobre uma superfície, ligações microscópicas vão formando-se e rompendo simultaneamente. As forças envolvidas, no caso, a de atrito e a normal, decorrem da interação entre moléculas nos pontos, onde as superfícies de contato do bloco e piso se tocam, conforme a movimentação. Nessa região, que se justapõem, ocorrem fortes adesões superficiais devido as forças interatômicas, caracterizado como a solda. Na ocorrência de movimento, o atrito sobre o material/objeto causa ruptura e reconstrução continua em novos pontos (GREF, 2006).

O módulo da força de atrito dinâmico é definido pela Eq. (1), que relaciona a Força Normal $(N)$ e o coeficiente de atrito $(\mu c)$, que é uma característica da superfície de contato,

$$
F_{a t}=\mu_{c} \cdot N
$$


De mesma forma, podemos definir o módulo da força de atrito estático máxima como,

$$
F_{a t_{\text {máx }}}=\mu_{e} \cdot N
$$

Onde, $\mu_{e}$ é o coeficiente de atrito estático. Diferente da força de atrito cinético, ela depedende da intensidade força externa aplicada (ou torque) ao sistema, podendo variar desde zero até um valor máximo, o sentido também pode variar, considerando um mesmo sólido e uma mesma superfície.

Inicialmente quando estudamos a força de atrito, exercida sobre um corpo em alguma superfície sólida, ignoramos completamente qualquer interação entre o corpo e o meio fluido ao seu redor, esta consideração será feita posteriormente quando se estuda a força de arrasto cujo meio pode ser um gás ou um líquido.

A descrição de uma abordagem teórica da queda vertical no ar com força de arrasto inercial, pode ser descrita com base em alguns modelos teóricos que podem ser consultados nas referências (ROSSINI, 2020; NUSSENZVEIG, 2013; BATCHELOR, 2020), este conteúdo de física, em geral é tradado em livros de mecânica dos fluidos em cursos mais avançados (BATCHELOR, 2020; ACHESON, 1990).

\section{PROCEDIMENTOS METODOLÓGICOS}

A Sequência didática (SD) desenvolvida foi aplicada na disciplina de Física 1, em uma turma do curso Superior de Licenciatura em Química, contendo 13 alunos, da Universidade Tecnológica Federal do Paraná, campus Campo Mourão. O assunto abordado, faz parte da ementa da disciplina.

Quando se iniciou o capítulo de Hidrostática, previamente aplicou-se aos alunos, um Quiz on line, contendo 10 questões sobre o assunto, com figuras/vídeos, através da utilização do software livre Kahoot, a fim de verificar os conhecimentos prévios dos alunos sobre o assunto (força viscosa, densidade, Empuxo, entre outros conceitos e aplicações) e resgatar os conceitos das Forças resistivas trabalhadas (forças de atrito e arrasto). Essa atividade foi realizada em $1 \mathrm{~h} / \mathrm{a}$.

$\mathrm{Na}$ aula seguinte, foi realizado uma explanação teórico-dialogada do conteúdo de Hidrostática, retomando o assunto de força de arrasto em meio gasoso para após introduzir a força de arrasto em meio líquido, utilizando todo o formalismo matemático detalhado e para de reforçar o aprendizado, foi atribuída como tarefa, uma lista de exercícios (2 h/a).

Foram realizadas atividades práticas reais e virtuais no decorrer do desenvolvimento do conteúdo, a fim de ajudá-los a reforçar os conceitos, como também a trabalhar determinados pontos, que sem o experimento seria de difícil compreensão, assim, para reforçar a formação dos conceitos sobre densidade, massa, volume, forças (peso, empuxo, normal), foi trabalhada uma simulação sobre densidade, do grupo PHET Colorado ( ${ }^{*} 6$ nota de rodapé) e após realizado discussões. Essa atividade teve duração de 1h/a.

Também foi explorado o Software Algodoo no qual a professora regente (FONTES, A. S.) construiu uma simulação virtual, onde foi possível variar a densidade da esfera, bem como sua massa, e variar ou anular o atrito. Simultaneamente ao movimento, pôde ser construído os gráficos da posição, velocidade e aceleração da esfera em queda, em função do tempo. 
Com essa simulação, os alunos puderam testar várias hipóteses. Essa atividade durou 25 minutos, e na sequência foi explorado uma simulação elaborada pelo professor David M. Harrison, a qual é hospedada no site do $N O A S$, sobre a queda de uma esfera em um meio viscoso, a qual permite variar valores de densidade da esfera e do líquido, viscosidade do líquido, raio da esfera e com essas variáveis obtém-se o peso da esfera, a força de arrasto, velocidade de decaimento; fornece também o número de Reynolds (BATCHELOR, 2002) e o gráfico da velocidade em função do tempo. Após foram realizadas as discussões. Essa atividade durou $1 \mathrm{~h} / \mathrm{a}$.

Como última atividade, foi organizado no laboratório de Física, uma prática sobre força de arrasto aplicada a uma esfera em movimento em três diferentes líquidos, a qual foi necessária $2 \mathrm{~h} /$ a para conclusão. Para tal foi montado um arranjo experimental, em que uma esfera metálica $\left(\rho=7,86 \mathrm{~g} / \mathrm{cm}^{3}\right)$ de $0,37 \mathrm{~g}$ massa e $0,448 \mathrm{~cm}$ de diâmetro, se desloca dentro de um tubo cilíndrico de $7,4 \mathrm{~cm}$ de comprimento e $1,34 \mathrm{~cm}$ de diâmetro, em três meios líquidos distintos: água $(\rho=1 \mathrm{~g} / \mathrm{cm} 3)$, óleo de soja $(\rho=0,883 \mathrm{~g} / \mathrm{cm} 3)$ e detergente Ipê $(\rho=1,02 \mathrm{~g} / \mathrm{cm} 3)$, com o intuito de compreender o comportamento da esfera nesses meios e obter as grandezas físicas envolvidas. Para tal, a esfera deve percorrer cada tubo por no mínimo três vezes consecutivas. Para a obtenção da massa, foi utilizado uma balança digital com precisão de 0,01 g e para a obtenção do diâmetro foi utilizado um paquímetro, com precisão de $0,02 \mathrm{~mm}$.

A opção pelo uso de esferas de ferro ou aço permite que elas sejam resgatadas do fundo da coluna de fluído com o auxílio de um imã; e com relação aos líquidos, foi devido em especial, à sua transparência, o que facilita a visualização e ao baixo custo em relação a outros materiais.

Para a análise do comportamento da esfera no meio, foi utilizado o Software Tracker instalado no notebook, o aplicativo Open Camera instalado no Smartphone. Após uso do Tracker, os pontos coletados foram inseridos no editor de planilhas do Excel a fim de obter as grandezas físicas. As discussões ocorreram logo após a execução de cada etapa e as avaliações se deram por meio de relatórios, discussões, tarefas e prova. Para facilitar a utilização da SD, descrevemos resumidamente no Tabela 1, a sequência de atividades. 


\begin{tabular}{|l|l|}
\hline $\begin{array}{l}\text { Quiz on line, contendo 10 questões sobre } \\
\text { o assunto, com figuras/vídeos, através da } \\
\text { utilização do software livre Kahoot. }\end{array}$ & $1 \mathrm{~h} / \mathrm{a}$ \\
\hline $\begin{array}{l}\text { Explanação teórico-dialogada do } \\
\text { conteúdo de Hidrostática } \\
\text { e de força de arrasto em meio líquido } \\
\text { com formalismo matemático. }\end{array}$ & $2 \mathrm{~h} / \mathrm{a}$ \\
\hline $\begin{array}{l}\text { Simulação envolvendo conceitos de } \\
\text { Hidrostática (densidade e empuxo), } \\
\text { utilizando o software PHET colorado. }\end{array}$ & $1 \mathrm{~h} / \mathrm{a}$ \\
\hline $\begin{array}{l}\text { Aplicação do Software Algodoo para } \\
\text { construção de uma simulação virtual } \\
\text { e atividade com simulador da plataforma } \\
\text { NOAS, sobre a queda de uma esfera em } \\
\text { um meio viscoso. }\end{array}$ & $1 \mathrm{~h} / \mathrm{a}$ \\
\hline $\begin{array}{l}\text { Atividade prática sobre força de arrasto, } \\
\text { aplicada a uma esfera em movimento em } \\
\text { três diferentes líquidos com o uso do software Tracker. }\end{array}$ & $2 \mathrm{~h} / \mathrm{a}$ \\
\hline
\end{tabular}

Tabela 1: Sequência das atividades realizadas.

\section{RESULTADOS E DISCUSSÕES}

O conteúdo de Hidrostática, foi iniciado com o uso de questionários, elaborados na forma de um Quizz, na plataforma do Kahoot, no qual, as primeiras questões versavam sobre força de arrasto no meio gasoso a fim de resgatar o conteúdo e, na sequência, questões para verificar o conhecimento prévio dos alunos sobre a força de arrasto no meio líquido. $\mathrm{Na}$ Figura 1, visualiza-se a forma como foi apresentada aos alunos uma das questões no telão da sala de aula (figura esquerda) e no Smartphone do aluno (à direita), nos dispositivos móveis aparecem quatro botões coloridos correspondentes a cada uma das respostas possíveis. A pontuação é calculada em função do número de respostas corretas ou incorretas e do tempo. 


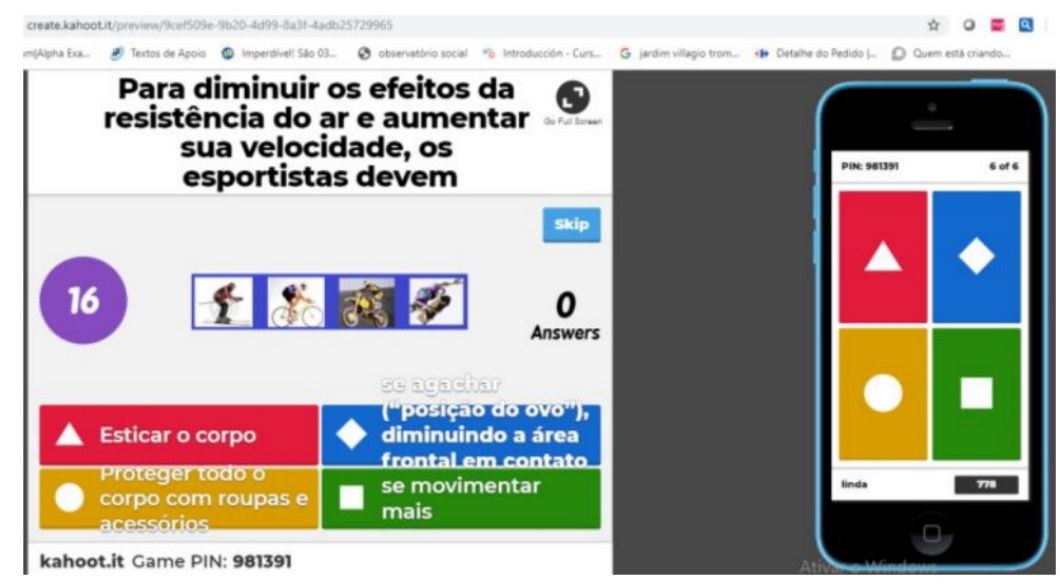

Figura 1: Modelo de questão na plataforma do Kahoot. Fonte: Print screen do Kahoot, 2020.

Após a aplicação das dez questões, o Kahoot forneceu um relatório detalhado com o número de acertos/erros em cada questão, por participante. Com estes dados foi possível identificar que: $80 \%$ dos licenciandos tinham pouco conhecimento sobre a força de arrasto no meio líquido. Mediante esta informação, a SD foi sendo organizada com mais atenção à formação dos conceitos, levando em consideração que estamos ensinando futuros professores.

Segundo Silva et al., (2018), o Kahoot contribui para a gamificação na sala de aula por possibilitar a utilização dos principais elementos de games, como estabelecer regras claras (tempo determinado para cada questão), feedbacks imediatos, pontuação por acerto, competição entre alunos/equipes, além de proporcionar prazer e diversão durante o processo de ensino e aprendizagem do discente.

Na atividade realizada no simulador Phet Colorado (Fig. 2), puderam ser testadas pelos acadêmicos, várias hipóteses, entre elas: selecionado a opção para corpos de massas iguais; e os volumes distintos e "fluído", água; foi possível visualizar que, ao introduzir o bloco de madeira de $5 \mathrm{~kg}$, o volume de líquido contido no recipiente que inicialmente possuía 100 litros de líquido, passou a ser 105, indicando que o volume do líquido deslocado é o mesmo do bloco, ou seja, 5 litros. Puderam perceber, que o bloco estava com metade do corpo para fora indicando que sua densidade é diferente a do líquido no qual ele se encontra. A partir desse momento começou a ser explorado o Princípio de Arquimedes.

Assinaladas as opções "mostrar forças de gravidade, flutuabilidade e contato"e as opções de "leituras de massas e forças (módulos)", foi possível explorar melhor todas as grandezas envolvidas na simulação e visualizar que a força peso tem o mesmo valor da força empuxo e por isso o bloco está em equilíbrio na superfície.

Ao adicionar um segundo bloco, o qual também possuía massa de $5 \mathrm{~kg}$ verificouse que ele afundava, e que possuía visualmente volume menor do que o primeiro. $\mathrm{O}$ valor do volume foi obtido através da equação $V=a^{3}$, onde "a"corresponde a aresta do bloco 


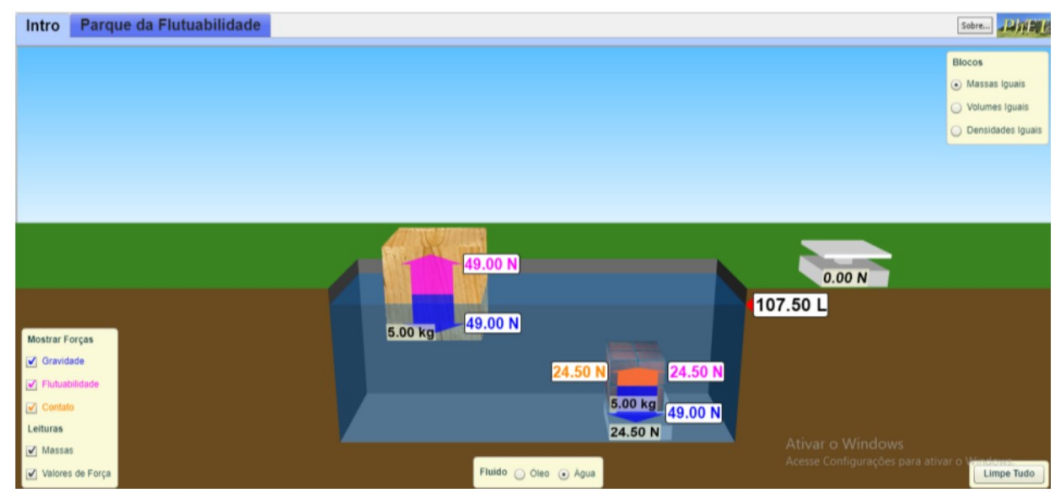

Figura 2: Simulação de Empuxo.

Fonte: <https://phet.colorado.edu/sims/density-and-buoyancy/buoyancy_pt_BR.html>

Foi possível compreender o Princípio de Arquimedes ao analisar que, para a obtenção do volume do corpo, o valor do líquido deslocado coincidiu com o valor obtido pela equação, a qual indicou 2,5 litros. Quando o bloco afundou, os alunos já constataram que a sua densidade é maior do que a do líquido no qual está mergulhado. Ao cair sobre uma balança disposta no fundo do recipiente, esta indicou um peso de 24,50 N. E fora da água, o peso de cada um dos blocos foi calculado pela segunda lei de Newton: $P=5 \mathrm{~kg}$. $9,8 \mathrm{~m} / \mathrm{s}^{2}=49 \mathrm{Kg} \cdot \mathrm{m} / \mathrm{s}^{2}=49 \mathrm{~N}$.

A força de empuxo foi obtida pela expressão de Arquimedes (GASPAR, 2001; JARDIM, 2014), onde $d_{F}$ é a densidade do fluído, $V_{F d}$ é o volume do líquido que foi deslocado e $g$ é a aceleração da gravidade. $E=d_{F} \cdot V_{F d} \cdot g$, onde organizando as unidades das grandezas no SI, $V_{F d}=2,5 l=0,0025 \mathrm{~m}^{3}$, e após substituindo, chegou-se a $E=1000 \mathrm{~kg} / \mathrm{m}^{3}$. $0,0025 \mathrm{~m}^{3} \cdot 9,8 \mathrm{~m} / \mathrm{s}^{2}=24,500 \mathrm{~kg} \cdot \mathrm{m} / \mathrm{s}^{2}=24,5 \mathrm{~N}$. O valor da densidade da água pode ser obtido facilmente, nos livros ou na internet.

Desta forma, a simulação considera que a força resultante é obtida por $F_{R}=P-E$. Assim, substituindo as informações da simulação, obtemos o valor indicado na balança $F_{r}=49,024,5=24,5 \mathrm{~N}$.

A simulação também permite mudar o líquido para óleo, onde verifica-se uma mudança nos valores da força de empuxo e consequentemente da força resultante a qual fica maior, pois a força de empuxo é menor.

Dessa forma foi possível observar que o bloco de madeira ao ser inserido no óleo, deslocou para 5,45 litros, ou seja, 0,45 litros a mais do que na água. E ao inserir o segundo bloco, esse deslocou os mesmos 2,5 litros, apresentados na água. Após foi realizado discussões para interpretar os resultados.

Em seguida, foram realizadas comparações dos blocos de massas iguais, nos meios água e óleo, clicando em aba "blocos"para testar as hipóteses com volumes iguais e depois com densidades iguais. Essa forma possibilitou explorar de forma mais completa o conteúdo.

Ao clicar na aba "Parque da flutuabilidade", pode-se variar material, massa, volume e densidade do material e do meio. Essa opção permite testar um valor opcional para o bloco (meu bloco). Essa simulação permitiu trabalhar, os conceitos enquanto se testavam as hipóteses viáveis. Esta atividade possibilita aos alunos a construir conceitos sobre massas, volumes e densidades dos materiais. 
$\mathrm{Na}$ atividade, realizada no software Algodoo, foi possível testar diferentes hipóteses (Fig. $3)$, entre elas, para a esfera, permitiu verificar o comportamento da esfera no decorrer do tempo, variar valores para a velocidade angular (linear), tamanho, material e atrito da esfera. Para o meio líquido permitiu variar a velocidade do líquido, volume, densidade do meio, atrito, e a aceleração da gravidade local, entre outros.

Foi possível também, acompanhar o movimento da esfera concomitante à construção do gráfico. O gráfico apresentado $(Y \times t)$ indica que a função é do 2ž. Grau, que pode ser explorado através do uso de derivadas e integrais (estabelecendo relações com o Cálculo Diferencial e Integral, fazendo a interdisciplinaridade com a matemática) para a obtenção da velocidade, deslocamento e aceleração da esfera no meio. Com esse experimento foi possível visualizar, em câmera lenta, o movimento da esfera dentro de um tubo preenchido com líquido.

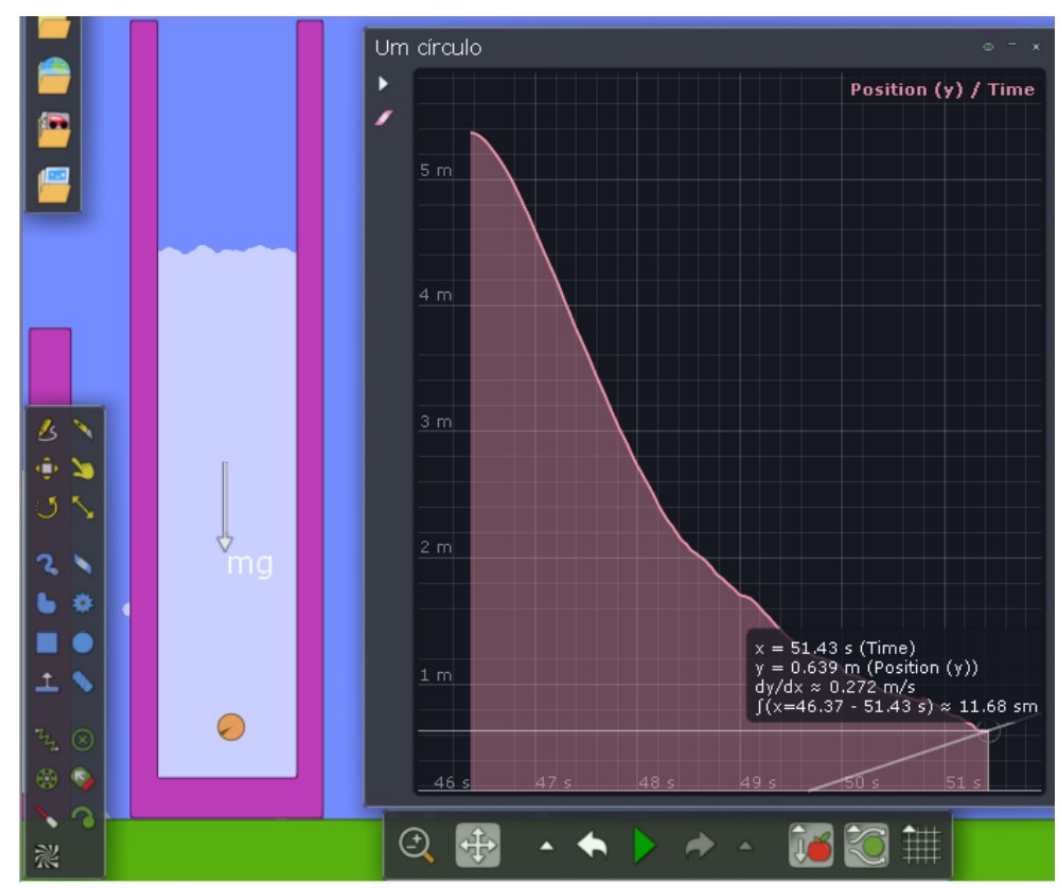

Figura 3: Exemplo da simulação construída no Software Algodoo.

Fonte: Print screen da tela do Software Algodoo, pelos Autores.

Na sequência, após os alunos já terem um melhor embasamento teórico sobre o assunto, foi trabalhada a simulação "Dropping a Ball in a Viscous Liquid"(Fig. 4), a qual foi utilizada para explorar mais a fundo o conteúdo, pois esta permite obter mais informações e testar muitas hipóteses (permite variar a densidade do líquido e da esfera, a viscosidade do líquido, o raio da esfera), e com base nos dados fornece o peso da esfera, o número de Reynolds, e o gráfico da velocidade da esfera em função do tempo. Com base na interpretação do gráfico, foi possível entender a velocidade limite e o tempo de movimento da esfera.

Esta simulação, permite aos alunos a reforçar o conteúdo e entender melhor algumas equações e conceitos que só haviam sido trabalhados na teoria, como o número de Reynolds (e sua dependência com a viscosidade e com a densidade do fluído, raio da esfera e velocidade); a relação da força viscosa com a densidade do líquido; a densidade da esfera e 
seu peso; como o raio da esfera influência nas forças peso e viscosa. Porém, a simulação não faz menção à força de Empuxo. A ausência desta força, foi notada logo de início pelos acadêmicos.

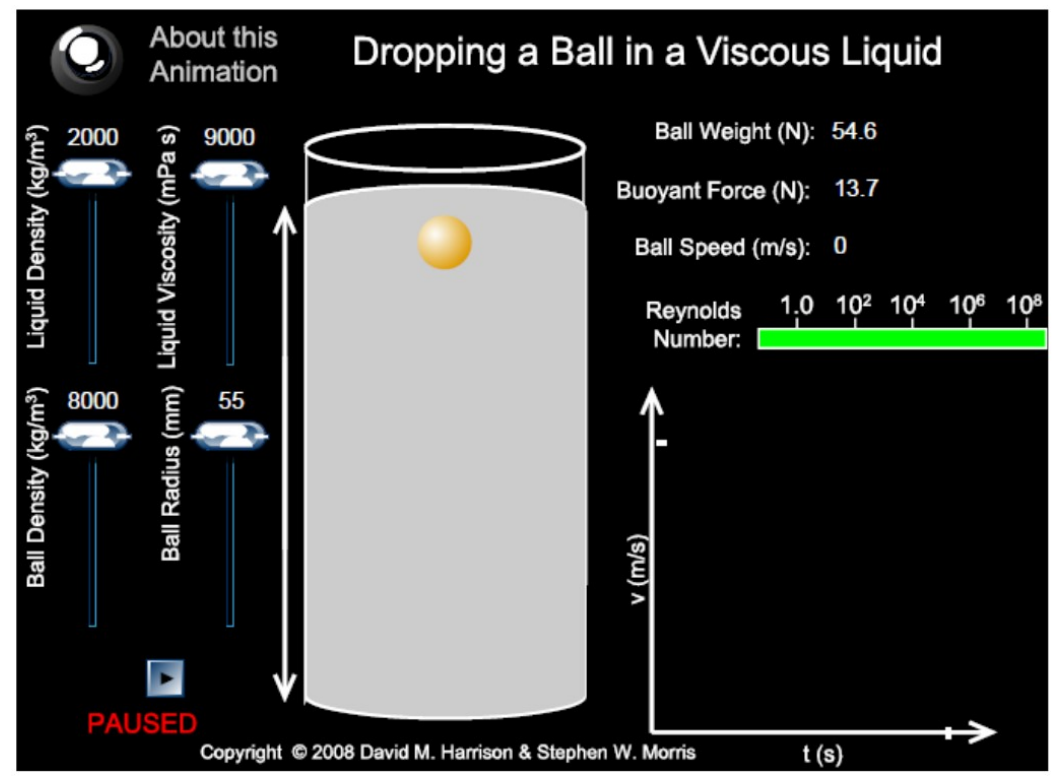

Figura 4: Movimento da esfera em meio viscoso

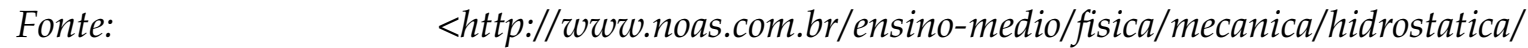
movimentoem-meio-viscoso/>

A atividade prática experimental associada à vídeo-análise (software Tracker), permitiu mostrar para os alunos, como um objeto se comporta em meios líquidos diferentes (tempo de queda, velocidade, trajetória e o movimento) e como a viscosidade do meio influencia nesse movimento, entre outras grandezas obtidas. Também, pode-se explorar com os alunos a construção dos gráficos, mostrando que são construídos baseados em informações reais.

Com esse recurso, foi possível todos observarem quadro a quadro o comportamento da esfera de metal, em câmera lenta, e perceber as diferenças em cada líquido utilizado (água, óleo e detergente). Inclusive foi possível visualizar que durante o todo deslocamento, a esfera só rotacionou aproximadamente $180^{\circ}$, para a surpresa de todos, pois achávamos que ela se deslocava rotacionando o trecho todo, e não foi o que se visualizou. Esse comportamento pôde ser observado devido a um ponto que marcamos na esfera com errorex e observarmos o movimento dele no decorrer do deslocamento vertical.

Após a seleção e análise do vídeo, os dados coletados foram transferidos e trabalhados no editor de planilhas do Excel. Isso possibilitou, a análise de algumas grandezas físicas e do comportamento do material. Desta forma, foi possível revisar alguns conceitos, quanto a interpretações e leitura de informações contidas nos gráficos (explorar a escala dos gráficos, unidades de medida, interpretação do comportamento das grandezas físicas envolvidas, entre outras informações).

Foi possível visualizar, que durante a queda da esfera na água ela se aproxima das paredes do tubo. Foi testado com esferas de diâmetros diferentes e visualizou-se que o comportamento fica melhor para esferas de diâmetro menores. Essa característica, confirma a observação de que a equação da força de Stokes, é conveniente apenas às esferas muito 
pequenas, de menor velocidade limite (terminal), cujo movimento no fluído é teoricamente caracterizado por números de Reynolds, inferiores a 0,5 (VERTCHENKO, L. VERTCHENKO, 2017).

Foi observado também, que a esfera se desloca com maior velocidade na água do que em relação aos outros dois meios (óleo e detergente), porém apenas no detergente foi perceptível uma diferença expressiva. Isso acontece devido a viscosidade do detergente ser maior, oferecendo mais resistência ao deslocamento da esfera.

Na Figura 5, está apresentado um print screen da tela do software Tracker contendo o arranjo experimental para a esfera no detergente. Através dos pontos da tabela de dados gerados no software, os gráficos puderam ser reproduzidos no editor de planilhas do Excel, a qual permitiu o ajuste e a inserção das equações.

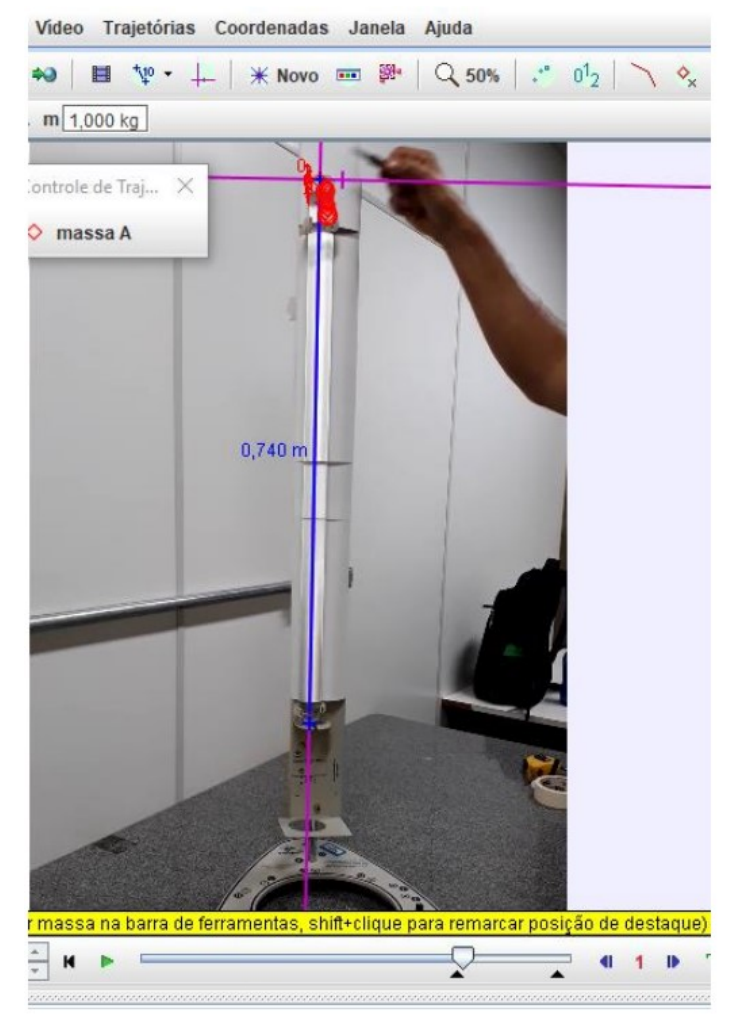

Figura 5: Print screen da tela do software Tracker contendo o arranjo experimental.

Fonte: Autores, 2020.

Esse procedimento foi realizado para todas as três substâncias utilizadas, e foram obtidos a velocidade da esfera é constante no decorrer do tempo, cujo valor está próximo de 0,82 $\mathrm{m} / \mathrm{s} ; 0,47 \mathrm{~m} / \mathrm{s}$ e $0,093 \mathrm{~m} / \mathrm{s}$, para a água, óleo e detergente, respectivamente. Assim, a aceleração é zero (confirmado graficamente), a posição variou de maneira linear com o tempo, confirmando o resultado.

Durante a prática, observou-se que a esfera se desloca mais rápido na água, seguida do óleo e por último no detergente, indicando que o detergente é mais viscoso que os demais meios. Por meio do software Tracker, foi possível obter o tempo de queda do corpo utilizado no experimento, o qual seria difícil (e menos preciso) sem esse recurso tecnológico gratuito. 
Após a análise do deslocamento da esfera nos três meios, o qual visa mostrar para os acadêmicos, como a viscosidade do líquido interfere no deslocamento, foi possível extrair dos gráficos o tempo que a esfera levou para chegar ao fundo do recipiente e sua respectiva velocidade, cujos dados encontram-se na Tabela 2.

\begin{tabular}{|l|r|r|r|}
\hline Material & Tempo de queda (s) & Velocidade terminal extraída do ajuste gráfico (m/s) \\
\hline Água & 0,90 & 0,82 \\
\hline Óleo & 1,60 & 0,47 \\
\hline Detergente & 7,74 & 0,093 \\
\hline
\end{tabular}

Tabela 2: Velocidade da esfera em decaimento nos meios viscosos.

Por meio dos gráficos, foi possível identificar como as diferenças de viscosidades interferem no deslocamento do material nos diversos meios, influenciando diretamente em sua velocidade. Com os dados foi possível calcular a forças peso, viscosa e de empuxo.

Após a execução das etapas, foi aplicado aos alunos um questionário, cuja questões estão apresentadas:

1. Se o meio fluído considerado for gasoso, haverá diferenças no movimento da esfera? E na equação?

2. O que se observou no tempo de queda da esfera nos três meios considerados.

3. O que se observa no comportamento do gráfico da $S \times t$, para os três meios considerados? Isso indica o que?

4. O que se observa no comportamento da $v \times t$, para os três meios considerados? Isso indica o que?

5. O que se observa no comportamento da $a \times t$, para os três meios considerados? Isso indica o que?

6. Faça um texto sobre o assunto, indicando as referências consultadas.

7. Reproduza o experimento utilizando, se possível, outros meios viscosos.

Os alunos responderam às questões de 1 a 5 sem dificuldades, porém na questão 6 tiveram muita dificuldade em encontrar material, informando no decorrer da tarefa que não encontravam o conteúdo nos livros de Física e nem na internet, indicando carência na literatura básica (ALVARENGA, 2003; CHAVES, 2007; GASPAR, 2001; HALLIDAY, 2016; TIPLER, 2009).

Na questão 7, os alunos realizaram a atividade em grupos, com destaque para os grupos A e B, onde o grupo A utilizou uma bolinha de gude de 1,6 cm de diâmetro e 28,15 g de massa para mostrar o comportamento da esfera na glicerina, no álcool gel e na água, em um tubo de vidro de $6 \mathrm{~cm}$ de diâmetro por $50 \mathrm{~cm}$ de comprimento. A grande dificuldade, foi em retirar a bolinha de gude ao término de cada deslocamento, tendo percebido que, em especial na água, há uma tendência da bolinha se aproximar das paredes do recipiente. 
Constatou-se também que, no início do deslocamento há uma pequena rotação da esfera, aproximadamente meio giro, tendo sido confirmado após marcar um pontinho na bolinha com errorex e acompanhar seu movimento. Esse fenômeno é o responsável pela mudança na direção da esfera, assim a necessidade de usar esferas pequenas para evita-lo, quando há colisões contra a parede a medida deve ser desconsiderada, pois isso irá influenciar no tempo de queda.

Com esse trabalho, foi possível explorar o comportamento da esfera, e obter várias grandezas físicas como peso, volume da esfera, viscosidade, força viscosa, empuxo e velocidade; e foi possível discutir sobre as vantagens de se trabalhar com esfera metálica (para facilitar a extração no tubo) e o problema do diâmetro da esfera em relação ao diâmetro do tubo.

O grupo B, praticamente reproduziu o experimento realizado pela professora regente com perfeição, tendo também filmado e após trabalhado com os dados no software Tracker, onde obtiveram o tempo de deslocamento, velocidade, entre outras grandezas, os grupos receberam sempre os mesmos materiais, o comportamento diferente desse grupo, provavelmente se deve as diferentes características dos alunos, pois nesse grupo havia alunos com maiores habilidades em manusear software.

Após a realização desta etapa, foi pedido aos alunos que avaliasse a SD, por meio do formulário elaborado no Google Docs, onde através dos comentários dos alunos indicaram que gostaram muito da forma como o conteúdo foi abordado, em especial sobre o Kahoot, com destaque para os depoimentos dos alunos A e B, respectivamente.

"Foi Excelente, adorei a experiência, é uma ferramenta muito didática"(Aluno A).

"Muito útil pois é uma forma diferente de ter um feedback dos conteúdos que os alunos estão estudando"(Aluno B).

Percebeu-se que, da forma como a SD foi planejada e aplicada, possibilitando ao licenciando fazer uso de diversas TDIC, com o intuito de compreender o fenômeno da força de arrasto em meio líquido, que é um conteúdo com poucas atividades práticas, apesar de fazer parte do ementário, possibilitando o aluno a interagir com os diversos recursos (não sendo um aluno passivo).

\section{CONSIDERAÇÕES FINAIS}

O trabalho conseguiu atingir seus objetivos, que foi o de elaborar uma SD para o ensino de força de arrasto em um meio líquido, utilizando atividades práticas com auxílio das TDIC. Estas atividades, tem potencial de melhorar o processo ensino-aprendizagem, além disso, as TDIC estão disponíveis para a maior parte dos nossos profissionais da educação. Nesse sentido, verificou-se, que a SD se tornou um material que apresenta muitas possibilidades de consulta para os professores de Física 1 com as sugestões de experimentos apresentados. Assim, foi fornecido ferramentas para os professores trabalharem este conteúdo de forma dinâmica e interessante, que levam o aprimoramento no processo ensino-aprendizagem. 
Ainda, sugere-se que, ao trabalhar em dinâmica, força de atrito e força de arrasto nos meios fluídos, já se faça uma menção sobre a aplicação, as diferenças nas equações e os conhecimentos prévios necessários para que esse conteúdo seja estudado, e que, após trabalhar hidrostática, esse assunto seja retomado.

O material elaborado poderá servir de consulta para professores, foi apresentado informações para subsidiar o professor para introduzir um conteúdo com presente nas ementas de física, de uma forma mais agradável e de melhor compreensão, além das ferramentas necessárias para complementar esse conteúdo de forma prática, com poucos recursos.

\section{AgRAdecimentos}

Agradecemos ao professor Dr. Fernando Lang da Silveira, da Universidade Federal do Rio Grande do Sul, Porto Alegre, pelas valiosas considerações sobre o trabalho, e ao professor Luiz Carlos Gomes Filho, do Colégio da Vila Militar, Campo Mourão, por ter identificado a carência de materiais sobre o assunto.

\section{REFERÊNCIAS}

ACHESON, D.J. Elementary Fluid Dynamics. Oxford Applied Mathematics and Computing Science Series. Jesus College Oxford. 1990.

ALVARENGA, B. A. e MÁXIMO, A. R. L. Física: Volume Único para o Ensino Médio. Editora Scipione: São Paulo, 2003 (Coleção de olho no mundo do trabalho).

BATCHELOR, G.K., An introduction to fluid dynamics (Cambridge University Press, Cambridge, 2002).

CALDAS, H.; SALTIEL, E; Sentido das Forças de Atrito e Movimento I. Rev. Bras. Ens. Fís., v.21, n. 3: p. 359-365, set. 1999.

CHAVES, A.; SAMPAIO, J. F. Física Básica Mecânica. Rio de Janeiro: LTC, 2007.

GASPAR, A. Física: Mecânica volume único. 1ł ed. São Paulo/SP: Editora Ática. 2001.

GAZOTTI-VALLIM, M. A.; GOMES, S. T.; FISCHER, C. R. Vivenciando inglês com Kahoot. The Especialist: Descrição, Ensino e Aprendizagem, v. 38, n. 1, 2017.

GOMES FILHO, L. C. Uma proposta de sequência didática para forças não conservativas. Dissertação de mestrado. Universidade Tecnológica Federal do Paraná. Programa de Pós-Graduação em Ensino de Física. Campo Mourão, 2019.

HALLIDAY, D.; RESNICK, R.; WALTER, J. Fundamentos de Física, volume 1 e 2: mecânica. Tradução Ronaldo Sergio de Biasi. -10. ed.-Rio de Janeiro: LTC, 2016. 
JARDIM, R. F. Determinação do coeficiente de viscosidade dos líquidos. Apostila. Instituto de Física. Universidade de São Paulo, São Paulo, 2014.

MARTINS, M. M.; RECCHI, A. M. DUGATO, D. A.; LEDUR, C. M. Tracker Software de análise de vídeos e imagens para o ensino de física e ciências. VI Encontro Regional Sul de ensino de Biologia. 2013.

MOREIRA, M. A. Unidades de Ensino Potencialmente Significativas UEPS. Aprendizagem Significativa em Revista. v. 1, n. 2, p. 43 63. 2011.

NUSSENZVEIG, H.M. Curso de Física Básica (Editora Blucher, São Paulo), v. 1. $5 \nmid$ ed. 2013.

OLIVEIRA, C., MOURA, S. P., SOUSA, E. R. TICS na educação: a utilização das tecnologias da informação e comunicação na aprendizagem do aluno. Pedagogia em Ação, v. 7, n. 1, 2015.

ORTIZ, J. Tutoriais software Tracker. Mestrado Profissional em Ensino Científico e Tecnológico URI/Santo Ângelo, 2015. Disponível em <http:/ / trackernoensinodafisica.blogspot.com.br / p/tutoriais.html> Acesso em: 06/03/2018.

ROSSINI, M. R., ALVES, M. J. AMORIN, L. H. CAMARGO FILHO, P. S. Estudo da influência do ar no movimento de queda dos corpos: uma comparação entre a previsão teórica e os dados experimentais usando o Tracker. Rev. Bras. de Ens. de física, v. 42, 2020.

TIPLER, P. A.; MOSCA, G. Física para cientistas e engenheiros, v.1 e 2; Mecânica, Oscilações e Ondas, termodinâmica. Tradução Fernando Ribeiro da Silva, Gisele Maria Ribeiro. Rio de Janeiro: LTC, 2009.

GREF/Grupo de reelaboração do ensino de Física. Universidade Federal do Estado de São Paulo/USP. Física 1: Mecânica. São Paulo: Edusp, 2006.

VERTCHENKO, L.; VERTCHENKO, L. Determinação da viscosidade por meio da velocidade terminal: uso da força de arrasto com termo quadrático na velocidade. Rev. Bras. Ensino Fís. vol.39 no.4, 2017. 